\title{
Neutropenic Fever in a Two-and-a-Half Month Old Girl: Severe Congenital Neutropenia
}

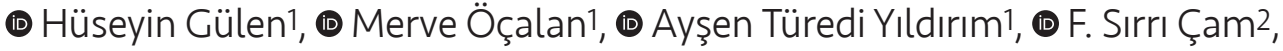 \\ (1) Hamide Betül Gerik Çelebi2 \\ 1 Manisa Celal Bayar University Faculty of Medicine, Department of Pediatrics, Manisa, Turkey \\ 2 Manisa Celal Bayar University Faculty of Medicine, Department of Medical Genetics, Manisa, Turkey
}

\begin{abstract}
Severe congenital neutropenia is a hereditary disease characterized by a low number of neutrophils occurring from the first months of life leading to severe infections. It is rare but threatens life because of severe infections. For this reason, early diagnosis and treatment of this disease is important. Here, we present a case of a two and a half month old girl who was admitted to our clinic with fever and absolute neutropenia was determined in her clinical course.

Keywords: Congenital neutropenia, ELA-2, G-CSF
\end{abstract}

\section{Introduction}

Congenital neutropenia is a disease that develops in bone marrow due to the arrest in promyelocyte or myelocyte maturation and differentiation (1). From the first month of life, clinical manifestations of staphylococcal, streptococcal, pseudomonas and fungal infections such as omphalitis, otitis media, pneumonia, abscess have been reported $(1,2)$. The peripheral blood neutrophil count is less than $500 / \mathrm{mm}^{3}$ (2). Eosinophilia, monocytosis, mild anemia and thrombocytosis may also appear in this disease.

The disease was originally described by Kostmann in 1956. The rate is approximately 1 or 2 in one million, equally prevalent in both male and female $(1,2)$. It usually shows an autosomal recessive transition. It may be either an autosomal dominant transition or sporadic transition. (2). At the molecular level, neutrophil elastase (ELA-2), HAX-1 (HS1related protein $\mathrm{X}-1)$, glucose-6-phosphatase catalytic subunit
3 (G6PC3), growth factor independent 1 - Wiskott-Aldrich syndrome protein) gene defects have been associated with this disease (1).

Granulocyte colony stimulating factor (G-CSF) is used in the treatment and most cases respond to treatment (3). Untreated patients may be lost early due to severe bacterial infections. Since the beginning of G-CSF usage as a treatment, the average life span has significantly increased. However, in these cases undergoing treatment, there is a risk of secondary myelodysplastic syndrome (MDS) and/or acute myeloid leukemia ( $A M L$ ) in the disease course (4). If patients are not lost from infections, cytogenetic changes can occur such as G-CSF receptor mutations in 12\% and monosomy 7 in $50 \%$. In the instances of cytogenetic changes, the risk of MDS and AML conversion increases. If these is no response to G-CSF, then stem cell transplantation is performed (1).

Severe congenital neutropenia is encountered quite rarely and mortality is high because of recurrent severe bacterial 
infections in the early stages of life. Genetic analysis is very important in its diagnosis and differential diagnosis. Severe congenital neutropenia should be kept in mind for children who have severe infections in the early stages of their life and blood counts should be carefully examined.

\section{Case Report}

A two and a half month old girl was brought in with a fever which had started the previous day and was measured the highest point at $40.1^{\circ} \mathrm{C}$. In her past history, she had been examined by a doctor due to complaints of redness and swelling of the left side of her neck on the $9^{\text {th }}$ day after birth. It was learned that these findings were assessed as a neck abscess and intravenous antibiotic treatment was administered. There was no history of consanguineous marriage or familial disease. On physical examination, the overall situation was good, the patient was conscious and her activity was normal. A systemic examination was normal. Laboratory values included leukocyte count of $6.700 / \mu \mathrm{L}$, absolute neutrophil count of $100 / \mu \mathrm{L}$, hemoglobin at $9.2 \mathrm{~g} /$ $\mathrm{dL}$, a platelet count of $330.000 / \mu \mathrm{L}$, mean corpuscular volume as $85 \mathrm{fL}$, mean corpuscular hemoglobin at $28 \mathrm{pcg}$. Peripheral blood smear showed that erythrocytes were normochromic and normocytic, $86 \%$ lymphocytes, 10\% monocytes, 4\% eosinophils, with noneutrophilsand noatypicalcells. C-reactive protein was $2.1 \mathrm{mg} / \mathrm{dL}$, procalcitonin was $0.2 \mathrm{ng} / \mathrm{mL}$. Liver and kidney function tests, electrolytes and urine examination were within normal limits. Urine and blood cultures were taken. Because of fever and severe neutropenia, empirical intravenous ampicillin and cefotaxime was started. On the third day, the control count of blood cells showed leukocyte as $4.700 / \mu \mathrm{L}$ with absolute neutrophil $0 / \mu \mathrm{L}$, hemoglobin $9.2 \mathrm{~g} / \mathrm{dL}$, platelet $306.000 / \mu \mathrm{L}$. In the peripheral smear; no neutrophil or atypical cells were observed, erythrocytes were normochromic and normocytic, monocytes were relatively increased. During the previous hospitalization due to the neck abscess in neonatal period, neutrophil counts were $<500 / \mu \mathrm{L}$. With these findings, congenital neutropenia was considered primarily in this case and a bone marrow aspiration was performed. In the bone marrow examination; cellularity was normal. Promyelocyte, myelocyte, metamyelocyte, band and mature neutrophil forms were absent. There was a relative increase in eosinophils and monocytes. Megakaryocytes were normal in number and morphologically. Erythroid series was also normal and depot cell and haemophagocytosis were not observed (Figure 1). Twenty-four and 72 hour cell culture were also performed from the bone marrow. This was not induced by phytohemagglutinin and evaluated malignant cells, which are usually spontaneous mitosis. Sequence analysis including all exon and exon-intron junction regions of ELANE / ELA-2, HAX1 and WAS gene for congenital neutropenia

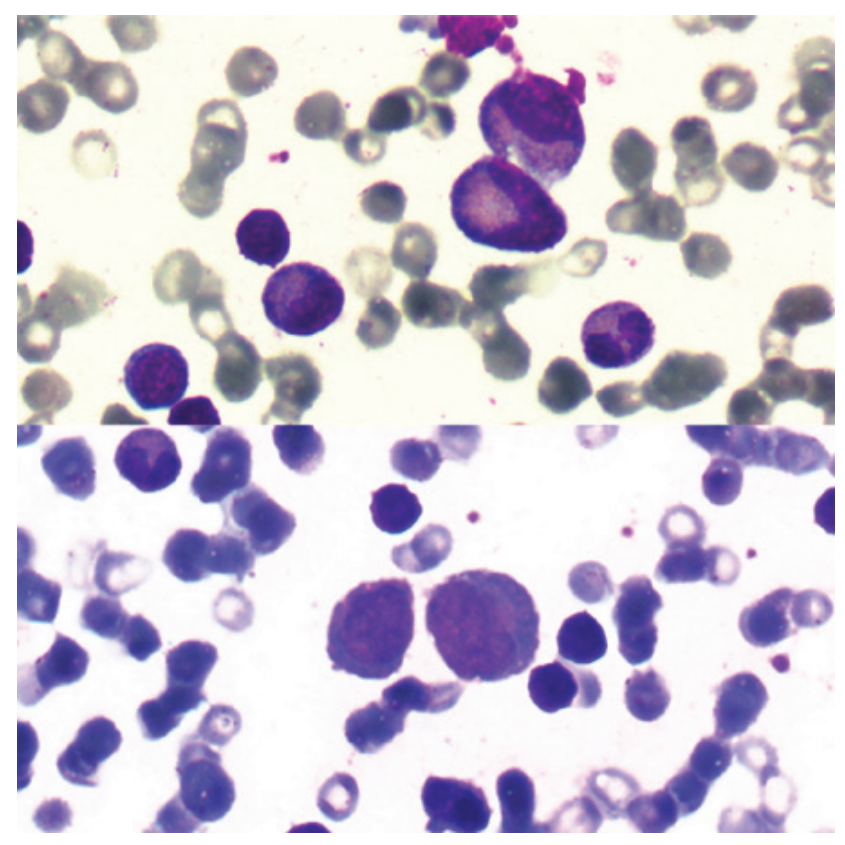

Figure 1. In bone marrow smear; promyelocyte, myelocyte, metamyelocyte, band and mature neutrophil forms were absent

was also performed by DNA isolation from the patient's peripheral venous blood. Bone marrow chromosome analysis revealed normal constitutive karyotype $(46, X X)$. In the genetic analysis, a heterozygous p.A57V (c.170C > T) missense amino acid mutation was observed in the second exon in the ELANE / ELA-2 gene; No mutations were found in the HAX1 and WAS genes. G-CSF therapy was started due to severe congenital neutropenia. After one week, the neutrophil count was determined as 2000/ $\mu \mathrm{L}$. Consent form was filled out by participant.

\section{Discussion}

Severe congenital neutropenia often manifests with clinical manifestations of omphalitis, abscess formation, otitis media, gingivitis and pneumonia within the first six months after birth $(1,2,4)$. Our patient was diagnosed with a neck abscess in the newborn period and there was severe neutropenia in her blood counts. Since there was an abnormal number of neutrophils from birth, severe congenital neutropenia was considered primarily and acquired neutropenic cases and cyclic neutropenia were excluded. Despite the treatment of the infection, neutropenia did not improve and infection-associated neutropenia was not considered primarily. Shwachman-Diamond syndrome was not considered for reasons such as no growth retardation, lack of skeletal anomalies and neutropenia occurring early in life. Other rare diseases which can lead to persistent severe neutropenia including hemophagocytic syndrome, reticular dysgenesis and dyskeratosis congenita were discounted after an analysis of the bone marrow aspiration findings. 
ELANE / ELA-2 mutations are the first identified genetic defects in autosomal dominant and sporadic severe congenital neutropenia and cyclic neutropenia $(5,6)$. Approximately 52 different ELANE / ELA-2 mutations have been reported to date $(7,8)$. Neutrophil elastase gene (ELANE / ELA-2) mutation is thought to result in a premature endoplasmic reticulum accumulation of unstructured protein in the cell due to increased stress and premature apoptosis in neutrophil precursor cells, thereby suppressing myelopoiesis (5). In our case, the heterozygous p.A57V (c.170C > T) missense amino acid mutation of the ELANE / ELA-2 gene was seen in the second exon. This mutation is a nucleotide $C$ nucleotide T replacement according to the ENSEMBL ENST00000263621 transcript and has been reported in the Human Gene Mutation Database under code CM094946. This mutation makes a difference in the amino acid sequence and causes a change in protein production.

No mutations were identified in HAX-1, WAS or G6PC3 genes, which are other mutations associated with severe congenital neutropenia.

In cases of severe congenital neutropenia, although sepsis-related mortality has decreased with the availability of appropriate antibiotics and regular G-SCF therapy in infections, the incidence of MDS or AML development in a 10 -year follow-up period has been reported to be $20 \%$. The risk of leukemia transformation is related to the myeloid arrest level in bone marrow, the type of ELANE mutation (C214R, C151Y), the presence of pancytopenia and G-CSF administration. This risk increases if the average dose in G-CSF injection is $\geq 10 \mu \mathrm{g} / \mathrm{kg} / \mathrm{day}$, the cumulative dose is $>10.000 \mu \mathrm{g} / \mathrm{kg}$ and given over a period of more than 10 years. The risk of MDS/AML appears to be around 2.3\% per year after 10 years on G-CSF. (9) In our case, G-CSF was administered at $3 \mu \mathrm{g} / \mathrm{kg} /$ day.

In conclusion, severe congenital neutropenia is a rare disease group that causes early death due to severe infections. Mutation analysis and genetic counseling are important for early diagnosis, treatment and prevention because of hereditary transition.

\section{Ethics}

Informed Consent: Consent form was filled out by participant.
Peer-review: Externally peer-reviewed.

\section{Authorship Contributions}

Surgical and Medical Practices: H.G., M.Ö., Concept: M.Ö., Design: M.Ö., Data Collection or Processing: M.Ö., Analysis or Interpretation: H.G., M.Ö., Literature Search: M.Ö., Writing: H.G., M.Ö.

Conflict of Interest: No conflict of interest was declared by the authors.

Financial Disclosure: The authors declared that this study received no financial support.

\section{References}

1. Barış S, Karakoç Aydıner E, Kıykım A, et al. The phenotypegenotype relationship in severe congenital neutropenia patients. Turk Pediatri Ars 2012;47:272-7.

2. Celkan T, Koç BŞ. Approach to the patient with neutropenia in childhood. Turk Pediatri Ars 2015;50:136-44.

3. Welte K, Zeidler C, Dale DC. Severe congenital neutropenia. Semin Hematol 2006;43:189-95.

4. Edeer Karaca N, Aksu G, Gulez N, et al. Clinical, Laboratory and Molecular Approach to Ten Children with Congenital Neutropenia. J Pediat Res 2016;3:7-12.

5. Boztug K, Klein C. Genetic etiologies of severe congenital neutropenia. Curr Opin Pediatr 2011;23:21-6.

6. Dale DC, Person RE, Bolyard AA, et al. Mutations in the gene encoding neutrophil elastase in congenital and cyclic neutropenia. Blood 2000;96:2317-22.

7. Horwitz MS, Duan Z, Korkmaz B, Lee HH, Mealiffe ME, Salipante S). Neutrophil elastase in cyclic and severe congenital neutropenia. Blood 2007;109:1817-24

8. Smith BN, Ancliff PJ, Pizzey A, Khwaja A, Linch DC, Gale RE. Homozygous HAX1 mutations in severe congenital neutropenia patients with sporadic disease: A novel mutation in two unrelated British kindreds. Br J Haematol 2009;144:762-70.

9. Rosenberg PS, Zeidler C, Bolyard AA, et al. Stable long-term risk of leukemia in patients with severe congenital neutropenia maintained on G-CSF therapy. Br J Haematol 2010;150:196-9. 